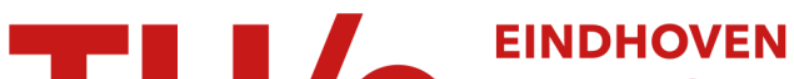 \\ UNIVERSITY OF \\ TECHNOLOGY
}

\section{Training software for chiral separations in capillary electrophoresis}

Citation for published version (APA):

Reijenga, J. C., Ingelse, B. A., \& Everaerts, F. M. (1997). Training software for chiral separations in capillary electrophoresis. Journal of Chromatography, A, 772(1-2), 195-202. https://doi.org/10.1016/S00219673(96)00943-0

DOI:

10.1016/S0021-9673(96)00943-0

Document status and date:

Published: 01/01/1997

\section{Document Version:}

Publisher's PDF, also known as Version of Record (includes final page, issue and volume numbers)

\section{Please check the document version of this publication:}

- A submitted manuscript is the version of the article upon submission and before peer-review. There can be important differences between the submitted version and the official published version of record. People interested in the research are advised to contact the author for the final version of the publication, or visit the $\mathrm{DOI}$ to the publisher's website.

- The final author version and the galley proof are versions of the publication after peer review.

- The final published version features the final layout of the paper including the volume, issue and page numbers.

Link to publication

\section{General rights}

Copyright and moral rights for the publications made accessible in the public portal are retained by the authors and/or other copyright owners and it is a condition of accessing publications that users recognise and abide by the legal requirements associated with these rights.

- Users may download and print one copy of any publication from the public portal for the purpose of private study or research.

- You may not further distribute the material or use it for any profit-making activity or commercial gain

- You may freely distribute the URL identifying the publication in the public portal.

If the publication is distributed under the terms of Article 25fa of the Dutch Copyright Act, indicated by the "Taverne" license above, please follow below link for the End User Agreement:

www.tue.nl/taverne

Take down policy

If you believe that this document breaches copyright please contact us at:

openaccess@tue.nl

providing details and we will investigate your claim. 


\title{
Training software for chiral separations in capillary electrophoresis
}

\author{
J.C. Reijenga*, B.A. Ingelse, F.M. Everaerts \\ Laboratory of Instrumental Analysis, Department of Chemical Engineering, Eindhoven University of Technology, P.O. Box 513, \\ $5600 \mathrm{MB}$ Eindhoven, The Netherlands
}

\begin{abstract}
A previously published steady-state simulation program for CE was extended with a sub-menu for chiral interaction. The interaction was modelled with a hypothetical (neutral) selector with properties similar to cyclodextrins. A three-type chiral interaction model was implemented in such a way that it was valid for both anionic and cationic analytes. User-defined chiral variables in the model were: the concentration of this chiral selector, the complex formation constants $(K)$ of both non-ionic and ionic analyte species, the relative $K$ differences between the two optical isomers (also for both non-ionic and ionic species) and the mobility of the analyte-selector complex, relative to that of the fully dissociated free analyte. In addition the following non-chiral variables are added: the dependence of the bulk viscosity on the chiral selector concentration and the dependence of the mobilities on the viscosity. Chiral components in the data base are simulated as mixtures of optical isomers with variable enantiomeric concentration ratios. These chiral parameters, together with the original features of the program, provide a very flexible training tool for chiral separations in capillary electrophoresis. For example, determination of the optimum chiral selector concentration can be done in seconds, using the simulation software. Although the software is intended mainly for training purposes, in cases where sufficient details of existing chiral selector-analyte combinations are available, the program is also suitable for method development of chiral separations in CE.

The performance of the program is illustrated with simulations, using chiral parameters obtained from literature (ibuprofen, fenoprofen, homatropine) and from our own experiments ( $m$-fenfluramine). Simulation results were compared with experimental electropherograms.
\end{abstract}

Keywords: Computer simulation; Enantiomer separation; Electrophoretic mobility; Viscosity; Buffer composition; Fenfluramine; Fenoprofen; Ibuprofen; Homatropine

\section{Introduction}

For training purposes, fast simulation programs based on steady-state models were found to be a useful addition to real laboratory experiments [1]. This was already obvious for techniques such as gas chromatography [2] and micellar electrokinetic chromatography [3], where elementary equilibrium thermodynamics can be readily used to model the temperature dependent partition between mobile and (pseudo) stationary phases.

${ }^{*}$ Corresponding author.
In capillary electrophoresis however, the fundamental basis for separation behavior is the concept of mobility, which together with basic acid-base equilibria, can be used to model the separation pattern in detail. A steady-state simulator based on such a model is now available for training purposes $[4,5]$. Although in that simulator, temperature and ionic strength effects are modelled, using emperical relations, complications such as complex formation and stereoselectivity were not taken into account. The use of electrophoretic techniques for separation of optical isomers has by now gained widespread attention. Recent reviews on the subject $[6,7]$, with 
hundreds of references, list many applications of the use of cyclodextrins in capillary zone electrophoresis, micellar electrokinetic chromatography, electrokinetic chromatography, as well as some other chiral selectors. In spite of the large number of references on chiral applications now available, quantitative data on modelling the chiral interaction are not easily obtained. A three-type interaction model for chiral interaction of acidic [8] and basic compounds [9] was clearly outlined by Rawjee et al. Both ionic and non-ionic interaction of either of the two optical isomers were quantified with corresponding complex formation constants. If, in addition the effective mobility of the free analyte and of the analyte-selector complex are known, a 6 parameter model is obtained that was confirmed to agree well with experimental results of selectivity optimization $[8,9]$. The present study was carried out for the benifit of a EU-sponsored TEMPUS Joint European Project 'New Curriculum in Chiral Chemistry', resulting in a curriculum given at the Comenius University in Bratislava during the academic years $1995 / 1996$ and 1996/1997. For the subject of capillary electrophoresis, simulation experiments with the previously published HPCESIM simulation program $[3,4]$ were planned as the introduction ${ }^{1}$. For the introduction to the chiral part of the practical course, this simulation program was extended with a submenu for chiral interaction, based on the above mentioned chiral parameters.

\section{Experimental}

\subsection{Simulation and experimental conditions}

The simulation software was programmed and compiled in PowerBasic version 3.0 (PowerBasic, Carmel, CA, USA). The computer hardware was an IBM-compatible PC with a Pentium 120 processor, 8 MB RAM, 1 GB Harddisk and VGA monitor. For running the software, a 386 type $\mathrm{PC}$ with $33 \mathrm{MHz}$ clock speed is a minimum requirement in order to keep calculation times to within a fraction of a

\footnotetext{
${ }^{1}$ The HPCESIM program can be obtained from the corresponding
} author. second. This enables the "instant" response necessary for use of short-cut keys.

Simulated and real experimental equipment conditions correspond to a usual commercial CE instrument (P/ACE, Beckman, Fullerton, CA, USA). Equipment conditions were: capillary $568 \mathrm{~cm}(500$ $\mathrm{mm}$ to detection) $\times 50 \mu \mathrm{m}$ I.D., voltage 10 or $20 \mathrm{kV}$. Injection 0.5 psi (ca. $3300 \mathrm{~Pa}$ ) during $5 \mathrm{~s}$. The instrument was thermostated at $25^{\circ} \mathrm{C}$. The ionic strength of the background electrolyte (BGE) was 10 $\mathrm{m} M$. BGEs were prepared with analytical grade chemicals from the usual sources (Merck, Darmstadt, Germany or Sigma, St. Louis, MO, USA). Heptakis2,3,6-tri-O-methyl- $\beta$-cyclodextrin (TRIME- $\beta$ ) was from Cyclolab (Budapest, Hungary). meta-Fenfluramine[N - ethyl - $\alpha$ - methyl - (trifluoromethyl)phenethylamine hydrochloride] as Ponderal ${ }^{\mathrm{TM}}$ (racemate) and as Isomeride ${ }^{\mathrm{TM}}$ were from Servier Technologie (Paris, France).

\section{Results and discussion}

\subsection{Chiral sub-menu}

The following user-defined variables were provided as model input: the concentration of the chiral selector, the complex formation constants of both non-ionic $\left(K_{1}\right)$ and ionic analyte species $\left(K_{2}\right)$, the relative $K$ differences $\left(\delta K_{1}\right.$ and $\left.\delta K_{2}\right)$ between the two optical isomers (also for both non-ionic and ionic species) and the mobility of the analyte-selector complex, relative to that of the fully dissociated free analyte. Chiral components in the data base are simulated as mixtures of optical isomers with variable enantiomeric concentration ratios.

When adding chiral selectors such as cyclodextrins to the BGE, the bulk viscosity often increases and as a result, the ohmic resistance of the capillary adjusts according to the decreased mobilities. These effects can be of the order of $10 \%$. The bulk viscosity was already included in the program as an independent variable. Previous experiments have shown that for $\beta$-CD polymer, the viscosity increases with the $\beta$ $\mathrm{CD}$ concentration according to a quadratic relation:

$\eta / \eta_{0}=1+a_{1} C_{\mathrm{s}}+a_{2} C_{\mathrm{s}}^{2}$ 
in which $\eta_{0}$ is bulk viscosity without chiral selector and $C_{\mathrm{s}}$ the analytical concentration of the chiral selector. The coefficients $a_{1}$ and $a_{2}$ are now included as program parameters. The mobility-viscosity relation in non-sieving media was estimated by monitoring the current at constant voltage as a function of the BGE viscosity. It was observed that the BGE mobilities $\mu$ decreased linearly with increasing viscosity according to the relation:

$\mu_{0}^{*} / \mu_{0}=1+a_{3} \eta / \eta_{0}$

in which $\mu_{0}^{*}$ is the mobility of the fully charged ion in water and $a_{3}$ is a constant that surprisingly was found to be 0.78 for the $\beta$-CD polymer mentioned [10]. In other cases, values of $a_{3}$ close to zero were observed [11]. For this reason, the constant $a_{3}$ was also included as a parameter.

Table 1 summarizes the additional chiral and non-chiral parameters with their allowed range of values. The interaction type listed refers to the definitions introduced by Rawjee et al. [8,9]. All these chiral parameters can be loaded and saved as buffer files, together with the other buffer parameters ( $\mathrm{pH}$, composition and ionic strength).

\subsection{Calculation of migration behavior}

Migration behavior in chiral systems is rather more complicated than in non-chiral systems. For example, an acidic analyte can be present in either of four species: as a charged or as a non-charged acid (equilibrium subject to $K_{\mathrm{a}}$ ), as a non-charged acid complexed with the chiral selector (subject to $K_{1}$ ) and as a charged acid complexed with the chiral selector (subject to $K_{2}$ ). Only two of these species migrate. The effective mobility of chiral components in the presence of chiral selector $\mu_{\text {eff }}$ is calculated from the mobility of the fully charged ion $\mu_{0}$ according (for monovalent anions) to the following equation [8]:

$\mu_{\mathrm{eff}}=\mu_{0} \cdot \frac{1+R_{\mathrm{M}} K_{2} C_{\mathrm{s}}}{1+K_{2} C_{\mathrm{s}}+\left(1+K_{1} C_{\mathrm{s}}\right)\left[\mathrm{H}_{3} \mathrm{O}^{+}\right] / K_{\mathrm{a}}}$

in which $R_{\mathrm{M}}$ is the mobility of the analyte-selector complex divided by the mobility of the fully ionized free analyte, $\left[\mathrm{H}_{3} \mathrm{O}^{+}\right]$the hydrogen ion concentration and $K_{\mathrm{a}}$ the acid dissociation constant of the analyte. The values of $\mu_{0}, R_{\mathrm{M}}$ and $K_{\mathrm{a}}$ are the same for both isomers, whereas the values of $K_{1}$ and $K_{2}$ may differ. For cations, Eq. (3) transforms into:

$\mu_{\mathrm{eff}}=\mu_{0} \cdot \frac{1+R_{\mathrm{M}} K_{2} C_{\mathrm{s}}}{1+K_{2} C_{\mathrm{s}}+\left(1+K_{1} C_{\mathrm{s}}\right)\left[\mathrm{OH}^{-}\right] / K_{\mathrm{b}}}$

in which $K_{\mathrm{b}}$ is the base dissociation constant. For multivalent ions, the denominators of Eq. (3) and Eq. (4) are accordingly adjusted. It should be emphasized that Eqs. (3) and (4) are valid only in cases where the analyte concentration is much smaller than $C_{\mathrm{s}}$. Consequently, the model does not describe sample overload.

In the software, two kinds of sample components are distinguished: those with potential chiral properties (the names are stored in an auxillary ASCIItype file) and those without such properties. The former are all treated alike, in that they are supposed to interact with the hypothetical chiral selector in

Table 1

Chiral parameters in the HPCESIM simulation program

\begin{tabular}{llcc}
\hline Variable & Dimension & Range from & To \\
\hline Interaction type & - & 0 (none-chiral) & 3 (ionic and non-ionic) \\
Selector concentration mmol/l & - & 0 & 200 \\
$K_{1}$ (non-ionic interaction) & $\%$ & 0 & 2000 \\
$\delta K_{1}$ (+ vs. - ) & - & -25 & +25 \\
$K_{2}$ (ionic interaction) & $\%$ & 0 & 2000 \\
$\delta K_{2}$ (+ vs. - ) & $\%$ & -25 & +25 \\
$R_{\mathrm{M}}$ (relative mobility) & $\%$ & 0 & 99 \\
Purity (\%+) & - & 0 & 99.9 \\
$a_{1}$ in Eq. (1) & - & 0 & 5 \\
$a_{2}$ in Eq. (1) & - & 0 & 100 \\
$a_{3}$ in Eq. (2) & & & 2 \\
\hline
\end{tabular}


exactly the same manner (all chiral complexation constants are the same for all chiral analytes).

The non-chiral analytes also interact with the selector, again with the same $K_{1}$ and $K_{2}$ values, but the $\delta K_{1}$ and $\delta K_{2}$ values are set to zero. Although not set as a separate goal for the current version of the program, in this way some form of (non-chiral) complexation can be modelled as well, with the limitation of a non-charged complex forming agent.

As long as the chiral selector concentration is zero, program performance remains exactly what it used to be. Only with non-zero selector concentrations is additional information is available: selectivity and resolution now refer to the separation of the respective optical isomers, resulting in zero values for non-chiral analytes. Other tabulated information on migration and dispersion always refers to the last migrating optical isomer.

\subsection{Visualization of results}

As an example, a number of cations with potential chiral properties were simulated with both $K_{1}$ and $K_{2}$ set to 100 . The $\delta K_{1}$ value is zero, $\delta K_{2}$ is set to $5 \%$, the relative mobility to $10 \%$ and the optical purity to $40 \%$. This is a type 2 interaction where only the ionic form of the analytes shows chiral discrimination by the selector. In Fig. la, the analysis under non-chiral conditions were shown, where the sepa-

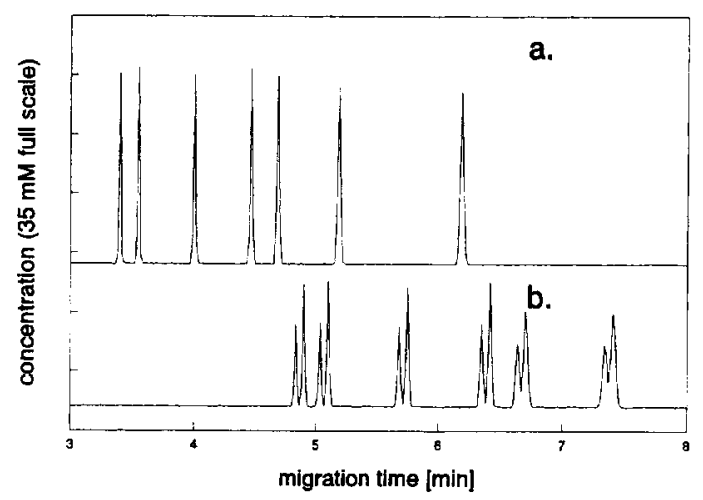

Fig. 1. Simulation of electrophoretic separation (in the elution order) of procaine, $\beta$-eucaine, cocaine, diocaine, psicaineleu, tetracaine and bupivacaine respectively without (a) and with 10 $\mathrm{m} M$ chiral selector (b). The buffer is a $10 \mathrm{mM}$ Tris-borate at $\mathrm{pH}$ 8.0. Further conditions as described in the Section 3.3 . ration is optimized by a $\mathrm{BGE} \mathrm{pH}$ in the range of the $\mathrm{p} K$ values of the analytes, so that they were separated according to their $\mathrm{p} K$ value. Fig. $1 \mathrm{~b}$ simulates a chiral selector concentration of $10 \mathrm{mmol} / 1$.

\subsection{Selectivity vs. resolution}

As seen from Fig. 1, chiral resolution is complete for the first few analytes. The last migrating components show less resolution because of two reasons. The degree of ionization of these is less, so that with a type 2 interaction less selectivity can be expected under these conditions. In addition to this difference in selectivity, resolution is also less because at increased migration times, increased dispersion due to diffusion is expected. From the point of selectivity, the model proposed in the literature $[8,9]$ appears to form a complete description of interaction phenomena. The resulting equations for selectivity are independent of all $\mu_{0}$ values, under the assumption that the charged analyte-selector complex mobility has no chiral distinction. Whether or not racemic mixtures can be separated, also depends on additional peak-broadening contributions from injection volume, concentration overload, diffusion, radial temperature gradient, detector cell length and time constant. These additional effects are included in the present simulations as well.

\subsection{Comparison with literature results}

Unfortunately, most publications on chiral separations lack quantitative information on the complex formation constants that can be used to model the analyte-solute interactions. In their publications describing the previously mentioned type 1-3 interaction mechanism, Rawjee et al. [8,9] give a number of examples for anionic and cationic sample components. Results of the optimization strategy were presented as selectivities vs. $\mathrm{pH}$ and selector concentration plots. It will be shown that in addition the present software is capable of calculating not only these selectivities, but also the resolution, often a more practical optimization criterion (as long as analysis time is considered as well). Some examples will now be outlined.

Mobilities and complexation constants for $\beta$ cyclodextrin interaction with fenoprofen and ibu- 
profen were determined [8]. Based on these values, a simulation was carried out at $\mathrm{pH} 4.5$, in a $200 \mathrm{mM}$ 2-(N-morpholino)ethanesulfonic acid (MES) buffer with $15 \mathrm{~m} M \beta-\mathrm{CD}$, using the equipment conditions as mentioned in the original article. In both instances there is a type 1 interaction with the $\beta-C D$, meaning stereoselective complexation of the non-ionic form of the analytes. Chiral selectivity surfaces as a function of $\mathrm{pH}$ and $\mathrm{CD}$ concentration [8] show monotonous increase of selectivity with decreasing $\mathrm{pH}$ and increasing $\mathrm{CD}$ content. Both components were simulated separately because the chiral conditions in the program are always the same for all chiral analytes present in the sample. The results (Fig. 2) agree reasonably well with the experimental electropherogram (Fig. 3).

In another example, the chiral separation of the cation homatropine [9], chiral interaction is of type 3 , meaning that both the ionic and non-ionic form of the analyte exhibit stereoselective interaction with the $\beta-C D$, although to a different extent. In this example, Rawjee et al. [9] found for $K_{1} 1328, \delta K_{1}$ $3.4 \%$ and $K_{2} 95.9, \delta K_{2} 8.4 \%$. In other words, the non-ionic form shows stronger but less stereoselective interaction, the ionic form shows weaker but more stereoselective interaction. Although in the practical concentration range of $\beta-\mathrm{CD}(0-15 \mathrm{mM})$ the migration sequence remains the same and there is a distinct selectivity optimum, at higher hypothetical concentrations there is a selectivity reversal. Fig. 4

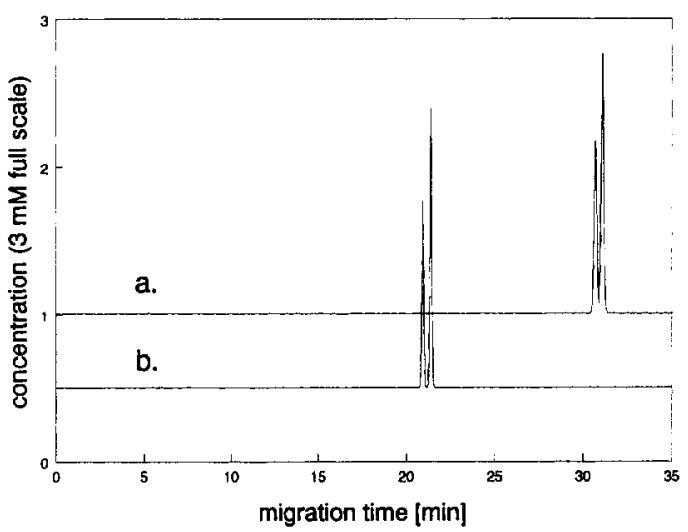

Fig. 2. Simulation of electrophoretic separation of ibuprofen (a) and fenoprofen (b) in $200 \mathrm{mM}$ MES, $\mathrm{pH} \mathrm{4.5,} \mathrm{chiral} \mathrm{selector}$ concentration $15 \mathrm{mM}$. Other conditions in Ref. [8].

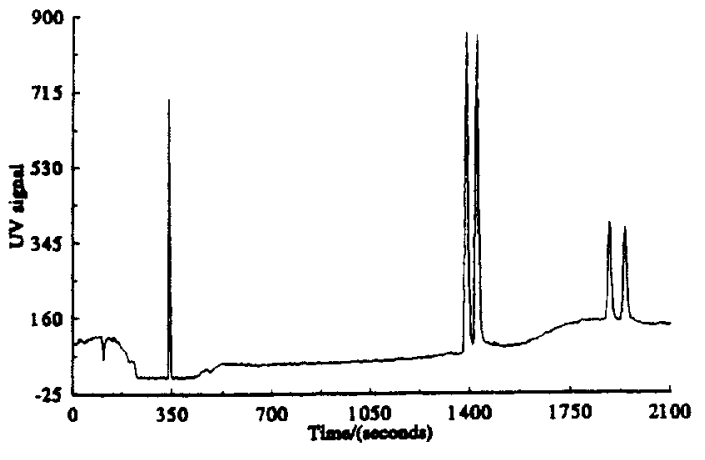

Fig. 3. Capillary electrophoretic separation of ibuprofen and fenoprofen respectively, conditions as in Fig. 2. Reprinted from Ref. [8] with permission.

illustrates analysis at three different chiral selector concentrations. Obviously, if possible, use should be made of $K_{2}$ because of shorter analysis times.

\subsection{Comparison with experimental results}

As another example, the chiral separation behavior of optical isomers of meta-fenfluramine was investigated with CE using TRIME- $\beta$ as chiral selector.

Fenfluramine is a base with listed $\mathrm{p} K$ of 9.1 [12] that is mainly administered as an anti-obesity drug. In the Netherlands, it is commercially available both as a racemic mixture (Ponderal) and as an optically pure $d$-isomer (Isomeride). The latter is the biologically active component. The optical purity of

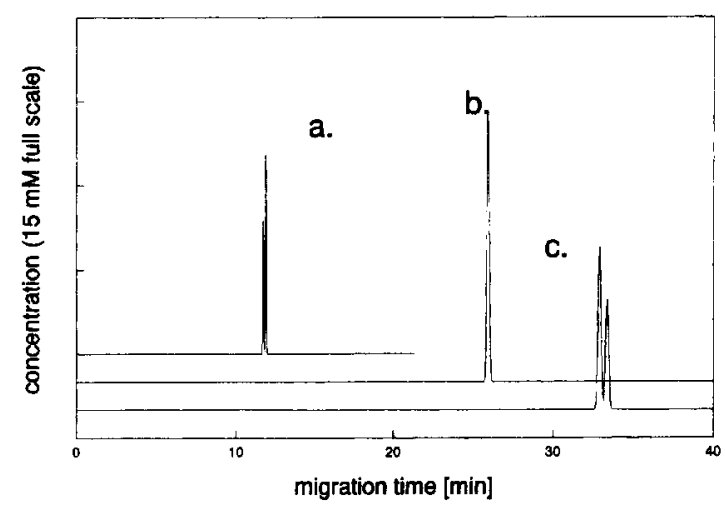

Fig. 4. Simulation of electrophoretic separation of homatropine at 5,25 and $50 \mathrm{mM}$ hypothetical chiral selector with model parameters and experimental conditions as in Ref. [9]. The buffer was $10 \mathrm{~m} M$ phosphoric acid-LiOH to $\mathrm{pH} 9.0$. 
Isomeride was investigated by Porrà et al. [13], using capillary electrophoresis with TRIME- $\beta$ as chiral selector. It amounted to ca. 98\%. This was confirmed by our analyses.

First, the $\mathrm{p} K$ and mobility of $m$-fenfluramine under experimental $\mathrm{CE}$ conditions were determined: $25^{\circ} \mathrm{C}$ and a ionic strength of $10 \mathrm{mM}$, slightly different from those reported $\left(15^{\circ} \mathrm{C}\right.$ and ca. $\left.100 \mathrm{mM}\right)$ [13]. Different BGE's were prepared by adding boric acid to a sodium hydroxide solution with a final concentration of $10 \mathrm{mM}$. Mobilities were determined by injection of mesityloxide as neutral marker, according to the recently published dual-marker method by Williams et al. [14]. The inverse values of the resulting effective mobilities were plotted vs. the hydroxide ion concentration in the range $\mathrm{pH} 8.6$ to 9.4. The following relation is valid for cations:

$\frac{1}{\mu_{\mathrm{eff}}}=\frac{1}{\mu_{0}}+\frac{10^{\mathrm{p} K}}{\mu_{0}} \cdot\left[\mathrm{OH}^{-}\right]$

From the intercept and slope of the linear regression line, shown in Fig. 5, the mobility at full protonation and the $\mathrm{p} K_{\mathrm{b}}$ value were calculated respectively. The $\mathrm{p} K_{\mathrm{a}}\left(14-\mathrm{p} K_{\mathrm{b}}\right)$ was determined as 10.1 , significantly higher than the literature value of 9.1 . The $\mu_{0}$ value was $19.38 \cdot 10^{-9} \mathrm{~m}^{2} / \mathrm{V} \mathrm{s}$.

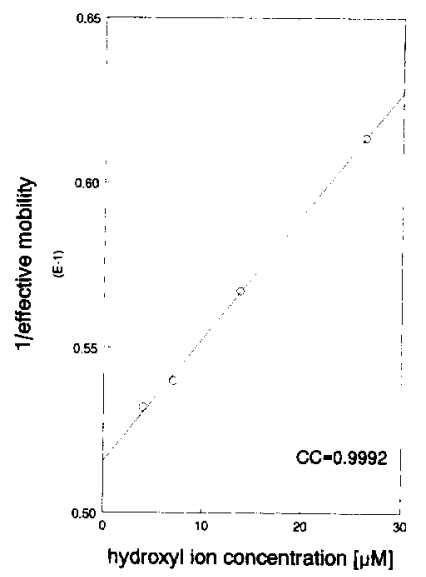

Fig. 5. Experimental determination of $\mathrm{p} K$ and $\mu_{0}$ values of $m$-fenfluramine at $25^{\circ} \mathrm{C}$ and $10 \mathrm{mM}$. The inverse effective mobility (mobility in units of $10^{-9} \mathrm{~m}^{2} / \mathrm{V} \mathrm{s}$ ) is plotted vs. the hydrogen ion concentration (in $\mu \mathrm{mol} / \mathrm{l}$ ). Further details see Section 3.6 .
In the experiments with non-zero TRIME- $\beta$ concentrations, the BGE viscosity $\eta$ was increased. This viscosity was found to be related to the TRIME- $\beta$ concentration in a non-linear fashion, according to Eq. (1), with $a_{1}=2.9$ and $a_{2}=40$. The mobilities were then corrected using Eq. (2) with $a_{3}=0.78$.

Next, using an $\varepsilon$-aminocaproic acid-acetate buffer of $\mathrm{pH} 5$ and ionic strength $10 \mathrm{mM}$, the effective mobilities of the optical isomers were determined at different concentration levels of TRIME- $\beta$ in the range $0-80 \mathrm{~m} M$. Under these conditions, $m$-fenfluramine was completely ionized, so that only $K_{2}$ values were relevant. Results are plotted in Fig. 6. From the slope of the linear regression lines, values of $K_{2}$ and $\delta K_{2}$ were determined. The $x$-axis intercept yielded the mobility of the analyte-selector complex. Table 2 gives a summary of results. Statistical analysis of the mobilities of the analyte-selector complexes has shown that there was no chiral distinction between the two values.

Finally, using $10 \mathrm{mM}$ sodium borate $\mathrm{pH} 9.46$ as $B G E$, effective mobilites were measured at different TRIME- $\beta$ concentrations. Under these conditions, both ionic and non-ionic forms of $m$-fenfluramine were present. The resulting effective mobilities, together with the values for $\mu_{0}, K_{2}, K_{\mathrm{b}}, R_{\mathrm{M}}$ and $\left[\mathrm{OH}^{-}\right]$were inserted into Eq. (4), which was then linearized as follows:

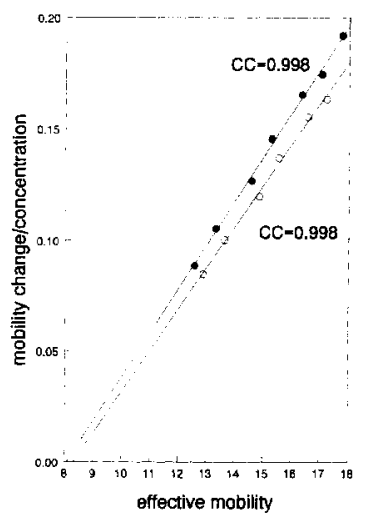

Fig. 6. Experimental determination of $K_{2}$ and $R_{\mathrm{M}}$ values of optical isomers of $m$-fenfluramine at $\mathrm{pH} 5$, using TRIME- $\beta$. The $\left(\mu_{0}-\right.$ $\left.\mu_{\mathrm{eff}}\right) / C_{\mathrm{s}}$ is plotted vs. $\mu_{\mathrm{eff}}$ with mobilities in units of $10^{-9} \mathrm{~m}^{2} / \mathrm{V} \mathrm{s}$, $C$, in $\mathrm{mol} / \mathrm{l}$. 
Table 2

Experimental values of electrophoretic and chiral parameters of $m$-fenfluramine (Conditions as in Section 2)

\begin{tabular}{lll}
\hline Parameter & Value & Standard deviation \\
\hline$\mu_{\mathrm{0}}$ & $19.38 \cdot 10^{-9} \mathrm{~m}^{2} / \mathrm{Vs}$ & $0.1 \cdot 10^{-9} \mathrm{~m}^{2} / \mathrm{V} \mathrm{s}$ \\
$\mathrm{p} K_{\mathrm{a}}$ & 10.1 & 0.05 \\
$\mu_{\text {complex }}$ & $8.2 \cdot 10^{-9} \mathrm{~m}^{2} / \mathrm{V} \mathrm{s}$ & $0.1 \cdot 10^{-9} \mathrm{~m}^{2} / \mathrm{V} \mathrm{s}$ \\
$R_{\mathrm{M}}$ & $41 \%$ & $0.5 \%$ \\
$K_{1}$ & 56 & 2.1 \\
$\delta K_{\mathrm{r}}$ & $0 \%$ & - \\
$K_{2}$ & 19.2 & 0.2 \\
$\delta K_{2}$ & $6.3 \%$ & $0.1 \%$ \\
\hline
\end{tabular}

$\left(1+R_{\mathrm{M}} K_{2} C_{\mathrm{s}}\right) \mu_{0} / \mu_{\mathrm{eff}}-1-K_{2} C_{\mathrm{s}}-\left[\mathrm{OH}^{-}\right] / K_{\mathrm{b}}$

$=K_{\mathrm{l}} C_{\mathrm{s}}\left[\mathrm{OH}^{-}\right] / K_{\mathrm{b}}$

Fig. 7 shows the left-hand side of Eq. (6) plotted vs. $C_{\mathrm{s}}$ in $\mathrm{m} M$ units, so that the slope of the line equals $K_{1}\left[\mathrm{OH}^{-}\right] / K_{\mathrm{b}}$. A linear relation is obvious between 0 and $40 \mathrm{~m} M$ TRIME- $\beta$, corresponding to $K_{1}$ values of 55.4 and 56.6, respectively. Standard deviations were 1.8 and 2.0 respectively, so that it can be safely assumed that there is no chiral discrimination of the non-ionic form of $m$-fenfluramine $\left(\delta K_{1}=0\right)$. According to the definition by Wren et al. [15], the $K_{1}$ values correspond to an optimum TRIME- $\beta$ concentration of $5 \mathrm{mM}$. At much higher concentrations $(60-80 \mathrm{mM})$, an unexplained deviation from the linear relation was observed. The $y$-axis intercept of the lines in Fig. 7. indicates that the free $m$-fenfluramine has an effective charge of 0.186 at this $\mathrm{pH}$.

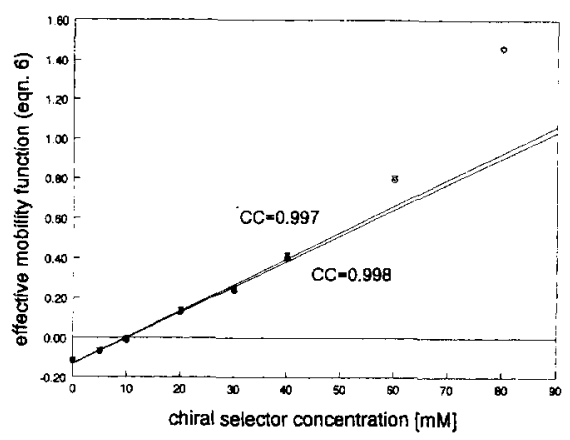

Fig. 7. The left hand side of Eq. (6) including the effective mobility (in units of $10^{-9} \mathrm{~m}^{2} / \mathrm{V} \mathrm{s}$ ) of $m$-fenfluramine enantiomers at $\mathrm{pH} 9.5$ vs. the concentration of TRIME- $\beta$.
Table 2 summarizes all chiral parameters of $m$ fenfluramine interacting with TRIME- $\beta$.

The separation of a typical Isomeride sample was now simulated, using the chiral parameter values in Table 2 as model input. Experimental conditions were $30 \mathrm{kV}$ in a $50-\mu \mathrm{m}$ capillary of length $400 \mathrm{~mm}$ (470 $\mathrm{mm}$ to the detector). The buffer was a $100 \mathrm{mM}$ $\beta$-alanine-acetate buffer with $\mathrm{pH} 4.2$ and $40 \mathrm{mM}$ TRIME- $\beta$. The simulation is shown in Fig. 8 , the actual separation, under the same conditions in Fig. 9. The comparison is satisfactory.

\section{Conclusions}

The above mentioned chiral parameters, together with the original features of the program, provide a very flexible training tool for chiral separations in

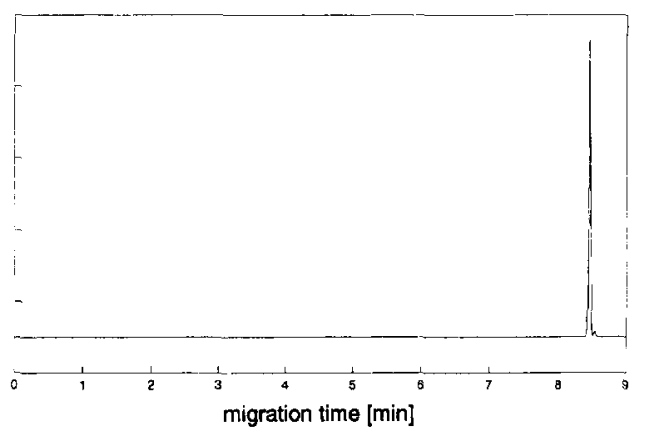

Fig. 8. Simulation of the chiral separation of a sample of Isomeride with $97 \%$ purity. Chiral parameters as in Table 2, other conditions as mentioned in Section 3.6. 


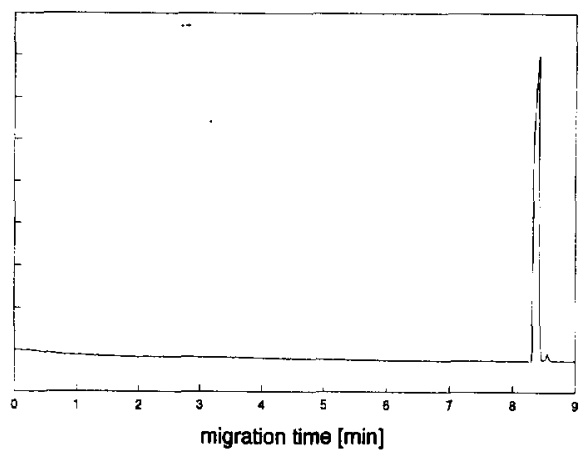

Fig. 9. Experimental determination of Isomeride with $97 \%$ optical purity, conditions identical to those of Fig. 8.

capillary electrophoresis. For example, determination of the optimum chiral selector concentration can be done in seconds, using the simulation software. Although the software is intended mainly for training purposes, in cases where sufficient details of existing chiral selector-analyte combinations are available, the program is also suitable for method development of chiral separations in $\mathrm{CE}$.

\section{Acknowledgments}

We gratefully acknowledge the gift of the Ponderal and Isomeride samples by Mrs. B.T. van Tuijl-
Knipscheer, Blixembosch Pharmacy, Eindhoven, Netherlands.

\section{References}

[1] J.C. Reijenga, J.H.P.A. Martens and F.M. Everaerts, Electrophoresis, 16 (1995) 2008-2015.

[2] J.C. Reijenga, J. Chromatogr., 588 (1991) 217.

[3] J.C. Reijenga and M. Hutta, J. Chromatogr. A, 709 (1995) 21.

[4] J.C. Reijenga and E. Kenndler, J. Chromatogr. A, 659 (1994) 403.

[5] J.C. Reijenga and E. Kenndler, J. Chromatogr. A, 659 (1994) 417.

[6] H. Nishi and S. Terabe, J. Chromatogr. A, 694 (1995) 245.

[7] S. Fanali, J. Chromatogr. A, 735 (1996) 77.

[8] Y.Y. Rawjee, D.U. Staerk and Gy. Vigh, J. Chromatogr., 635 (1993) 291.

[9] Y.Y. Rawjee, R.L. Williams and Gy. Vigh, J. Chromatogr. A, 652 (1993) 233.

[10] B.A. Ingelse, Thesis, Eindhoven University of Technology, in preparation.

[11] J.C. Reijenga, G.V.A. Aben, Th.P.E.M. Verheggen and F.M. Everaerts, J. Chromatogr., 260 (1983) 241.

[12] D.W. Newton and R.B. Kluza, Drug Intel. Clin. Pharm., 12 (1978) 546.

[13] K. Porrà, M.G. Quaglia and S. Fanali, Chromatographia, 41 (1994) 383.

[14] R.L. Willams and G. Vigh, Anal. Chem., 68 (1996) 1174.

[15] S.A.C. Wren and R.C. Row, J. Chromatogr., 603 (1992) 235. 